\title{
Insulin-like growth factor I and II preserve myocardial structure in postinfarct swine
}

\author{
A-A Kotlyar, Z Vered, I Goldberg, P Chouraqui, D Nas, E Fridman, Z Chen-Levy, \\ S Fytlovich, G Sangiorgi, L G Spagnoli, A Orlandi, N Savion, M Eldar, M Scheinowitz
}

\begin{abstract}
Background-Insulin-like growth factors (IGF) I and II improve myocardial function after coronary occlusion in different animal models.

Objectives-To investigate the mechanism of improved myocardial function after administration of IGF-I or IGF-II in acute myocardial infarction.

Methods-Female pigs (mean (SD) weight 25 (5) $\mathrm{kg}$ ) were subjected to acute myocardial infarction by microembolisation with $75-150 \mu \mathrm{m}$ affigel blue beads. The beads contained and slowly released $150 \mu \mathrm{g} /$ pig of IGF-I $(n=6)$, IGF-II $(n=6)$, or pig albumin $(n=6)$. Echocardiography, perfusion imaging, and haemodynamic measurements were performed before infarction and during four weeks after infarction. Regional wall motion of different left ventricular segments was scored semiquantitatively on the basis of a three point scoring system, from normal $=0$ to dyskinesia $=3$. Serum cardiac troponin I concentration was measured before, immediately after, and three hours after the infarct. Excised hearts were analysed for actin, desmin, blood vessel density, and DNA laddering within the infarct, border, and normal myocardial areas.

Results-Myocardial function of the infarct related area improved significantly during the four weeks of follow up in both the IGF groups $(p=0.01)$. Myocardial perfusion, heart rate, and blood pressure were similar in all the animals during the study. Treated animals had lower serum cardiac troponin I concentration $(p=0.001)$, more actin in the border area $(p=0.01)$ and infarct area $(\mathrm{p}=0.0001)$, and reduced DNA laddering in the infarct area compared with the controls $(p<0.05)$. IGF groups had more blood vessels in the border area $(p=0.04)$ and the infarct area $(\mathrm{p}=0.003)$.
\end{abstract}

The Neufeld Cardiac Research Institute, Tel Aviv University, Tel-Hashomer 52621, Israel

A-A Kotlyar

$M$ Eldar

M Scheinowitz

The Heart Institute, Sheba Medical Centre, Tel-Hashomer, Israel Z Vered

P Chouraqui

Department of Pathology, Sheba Medical Centre

I Goldberg

D Nas

E Fridman

Clinical Chemistry

Laboratory, Asaf

Harofe Medical

Centre, Zrefin, Israel

Z Chen-Levy

$S$ Fytlovich

Department of

Surgery, Universita' di

Roma-Tor Vergata,

Rome, Italy

G Sangiorgi

L G Spagnoli

A Orlandi

Goldschleger Eye

Research Institute, Tel

Aviv University, Israel

N Savion

Correspondence to:

Dr Scheinowitz

mickeys@post.tau.ac.il

Accepted 8 August 2001

Conclusions-Both types of IGF improved myocardial function and the improvement was associated with preservation of myocardial structure. IGF-I was more effective than IGF-II.

(Heart 2001;86:693-700)

Keywords: myocardial infarction; growth factors; ventricular function; troponin I

Insulin-like growth factors (IGF) I and II are single chain polypeptides consisting of 70 amino acids (IGF-I) and 67 amino acids (IGFII), respectively. IGF-I and IGF-II are structurally and functionally related to each other and to insulin. Adult cells are the physiological source of IGF-I, while embryonic cells are the source of IGF-II. ${ }^{1}$

IGF-I is known to mediate many if not most of the anabolic effects of circulating growth hormone, including those in the heart. ${ }^{12}$ In growth hormone deficiency, treatment with human recombinant growth hormone was found to increase cardiac output and left ventricular ejection fraction, the effect being similar to that observed following IGF-I treatment. ${ }^{1}{ }^{2}$ Moreover, IGF-I was found to have a direct effect on myocardial cells. Constitutive overexpression of IGF-I positively influenced the performance of myocytes from transgenic mice by enhancing shortening velocity and cellular compliance, and prevented activation of cell death in viable mouse myocardium after infarction. ${ }^{34}$ Exogenous administration of IGF-I has been shown to improve cardiac function in cardiomyopathy, ischaemia and reperfusion, and heart failure, while IGF-II improves myocardial function after acute infarction..$^{5-8}$

Both IGF variants are associated with myocardial angiogenesis. IGF-I is involved in the inflammation linked angiogenic process after microembolisation in porcine hearts. ${ }^{9}$ Raised IGF-I also promoted neovascularisation by increasing vascular endothelial growth factor (VEGF) gene expression. ${ }^{10}$ The direct angiogenic activity of IGF-II has been observed in the quantitative chick chorioallantoic assay. ${ }^{11}$ IGF-II also increased VEGF mRNA in human hepatoma cells. ${ }^{12}$

Both IGF variants have been shown to increase myocardial function but the mechanism of the improvement remains unclear. Our aim in the present study was to examine whether IGF-I or IGF-II attenuates myocardial dysfunction following acute myocardial infarction through preservation of myocardial proteins or enhancement of myocardial blood vessel density.

\section{Methods}

ANIMAL MODEL

The animals were handled according to the Guide for the care and use of laboratory animals published by the US National Institute of Health (NIH publication No 85-23, revised 1996), and the study was conducted under the supervision of a certified veterinarian, following the approval by the institutional animal care and use committee.

Eighteen female pigs (mean (SD) weight, 25 (5) $\mathrm{kg}$ ) were subjected to acute myocardial infarction using distal microembolisation, as previously described. ${ }^{813}$ The animals were randomly divided into three groups: six pigs received IGF-I $(150 \mu \mathrm{g} / \mathrm{pig})$, six received 
IGF-II $(150 \mu \mathrm{g} / \mathrm{pig})$, and six received pig albu$\min (150 \mu \mathrm{g} / \mathrm{pig})$. Echocardiographic functional studies were performed before and after infarction and during the four week follow up period of the study.

INDUCTION OF ACUTE MYOCARDIAL INFARCTION The animals were premedicated with $2-3.5 \mathrm{mg} /$ $\mathrm{kg}$ azaperone intramuscularly. After intravenous administration of thiopentone (thiopental) sodium $(10-12 \mathrm{mg} / \mathrm{kg})$, general anaesthesia was achieved using halothane $1.5-2 \%$ in oxygen, inhaled through an endotracheal tube. Left coronary artery catheterisation was performed through the femoral artery using the Seldinger technique. An over-the-wire intracoronary balloon $(2.0$ or $2.5 \mathrm{~mm})$ was advanced into the distal left anterior descending coronary artery or into one of its branches. After the balloon had been inflated to $6 \mathrm{~atm}$ for 30 seconds, $50 \mu \mathrm{l}$ of affigel blue non-biodegradable beads (75$150 \mu \mathrm{m}$, Bio-Rad Laboratories, California, USA) suspended in $0.5 \mathrm{ml}$ of saline were injected through the distal lumen of the balloon catheter to induce a microembolisation infarct of the distal left anterior descending coronary artery territory. The experimental groups received beads containing recombinant human IGF-I or IGF-II $(150 \mu \mathrm{g} / \mathrm{pig})$, while the control group received beads containing pig albumin $(150 \mu \mathrm{g} / \mathrm{pig})$. IGF-II was given in phosphate buffered saline (PBS) and IGF-I was freeze dried and dissolved in $0.1 \mathrm{M}$ acetic acid, after which it was diluted in PBS to $5 \mathrm{mg} / \mathrm{ml}$. Thus the beads were used both to induce acute myocardial infarction and to provide a gradual (slow) release delivery system of the peptides $\left({ }^{813}\right.$ and unpublished data).

ECHOCARDIOGRAPHY

To evaluate regional and global left ventricular function, parasternal long and short axis cross sectional echocardiography (77020A Ultrasound, Hewlett Packard, Andover, Massachusetts, USA) was carried out under general anaesthesia at baseline (preinfarction), immediately after the infarct, and two hours, two weeks, and four weeks after the infarct. Short axis echocardiographic images obtained at the basal, mid-papillary muscle, and apical levels were recorded on half inch videotapes and analysed by two unbiased investigators. Left ventricular cavity area, myocardial thickening, and myocardial shortening were measured to assess left ventricular global myocardial function. Images were divided into septal, anterior, lateral, posterior, and inferior wall segments within the left ventricle, on the basis of the recommendations of the American Society of Echocardiography. ${ }^{14} \mathrm{Ab}-$ normalities of regional wall motion in the different left ventricular segments were scored as follows: 0, normal; 1, hypokinesia; 2, akinesia; 3, dyskinesia. ${ }^{14}$ In this three point scoring system, the segmental wall motion is inversely related to the score. Calculations of global left ventricular function were based on the summation score of all segments for each animal at each time period. No regional dysfunction following myocardial infarction was observed at the basal parts of the heart and no changes were observed in global left ventricular function; thus these "segments" received the score of 0 (normal motion) and are not reported in detail.

\section{PERFUSION IMAGING}

To evaluate regional and global left ventricular perfusion, technetium-99m tetrofosmin was injected intravenously $(12 \mathrm{mCi})$. A 10 minute image was obtained in the anterior oblique projection 30 minutes after the injection. Using a mobile gamma camera (Apex 215M, Elscint, Haifa, Israel), imaging was performed before myocardial infarction, immediately after myocardial infarction, and two and four weeks later. At the four week time period, myocardial perfusion was also measured following adenosine administration. Adenosine was given until a $30 \%$ reduction in mean systolic blood pressure was recorded. ${ }^{15}$ Perfusion images were obtained at basal, mid-papillary muscle, and apical levels.

Data were stored on magnetic disks for subsequent analyses. Images at each time period and at each level were projected on a computer screen and visually divided into septal, anterior, lateral, posterior, and inferior left ventricular wall segments. ${ }^{16}$ An unbiased investigator made a qualitative assessment of the perfusion of each left ventricular segment according to a standard technique. ${ }^{16}$ In this five point scoring system, the segmental perfusion is inversely related to the score and directly related to the damage in myocardial perfusion, with normal $=0$.

HAEMODYNAMIC MEASUREMENTS

Arterial blood pressure was monitored continuously through a catheter positioned in the femoral artery and recorded at baseline (preinfarction), immediately after the infarct, two hours after the infarct, and four weeks later, with measurements during adenosine administration at that time as well, using a physiological pressure transducer (60-800 Trantec, Baxter Health Corporation, Uden, Holland) connected to a polygraph system (Nihon Kohden, Tokyo, Japan). Heart rate was monitored and recorded at the same time as blood pressure.

SERUM TROPONIN

For serum cardiac troponin I evaluation, venous blood samples from each animal were collected at baseline, immediately after infarction (20-30 minutes), and three hours after infarction. The samples were centrifuged for five minutes at $1400 \mathrm{~g}$, and the separated serum from each animal was frozen at $-80^{\circ} \mathrm{C}$. A microparticle enzyme immunoassay was used to determine cardiac troponin I concentration in the serum samples. ${ }^{17}$ Quantitative determination was performed on the AxSYM system (Abbot Diagnostics, Abbott Park, Illinois, USA), using their troponin I reagent pack for in vitro diagnostic use.

\section{PATHOLOGICAL PREPARATION}

Four weeks after the infarction the animals were reanaesthetised and killed. The chest was opened and the heart was quickly excised and removed. Samples were collected from representative macroscopically determined infarct areas (white), peri-infarct border areas (white 
with red), and normal areas (red) (fig 1). The samples from normal myocardial areas were collected from the opposite side to the infarcted left ventricular wall. The samples $(0.5-1.0 \mathrm{~g})$ were immediately frozen in liquid nitrogen and stored at $-80^{\circ} \mathrm{C}$, or cut and fixed in $10 \%$ buffered formaldehyde and embedded in paraffin for subsequent analyses. In order to verify that the material collected was appropriately defined, all stained slides were microscopically analysed by an unbiased pathologist.

\section{BLOOD VESSEL DENSITY}

Slides from each myocardial area in each animal ( $5 \mu \mathrm{m}$ thick) were stained with factor VIII (Von Willebrand factor, VWF) antibody (1:200), using the Histostatin-SP Zymed kit (San Francisco, California, USA). Nine fields on each slide representing each myocardial area were randomly chosen for counting stained blood vessels. Counting was performed using a grid inserted into the eyepiece $\left(1 \mathrm{~cm}^{2}\right.$ divided into $10 \times 10$ squares of $1 \mathrm{~mm}^{2}$, at $\times 400$ magnification). All stained vessels with lumens dissected by the vertical lines were counted. ${ }^{18}$ Vascular counts for each slide were calculated as the sum of the counts in nine fields. The number of blood vessels per area in each group is presented as mean (SD).

MYOCARDIAL ACTIN AND DESMIN

Slides were stained with monoclonal mouse IgG2a $\alpha$-actin and monoclonal mouse $\operatorname{IgG}_{1} \kappa$ $\alpha$-desmin, respectively, using the Histostatin-SP Zymed kit. ${ }^{19}$ The quantitative evaluation of actin and desmin stained areas was performed at $\times 150$ magnification. The slides were projected on a PC image monitor, using a Galai Scannaray/ Supercue-3 computerised coloured image analyser (Galai, Migdal Haemek, Israel). Nine fields of $23.55 \times 10^{3} \mu \mathrm{m}^{2}$ from each myocardial area of each animal were randomly chosen for evaluation. The values of actin and desmin were expressed as a percentage of the total stained area at each field and presented as the mean (SD) of nine fields.

\section{DNA LADDERING}

The frozen myocardial samples were used for biochemical analyses. To identify and quantify DNA fragmentation associated with myocyte death, ligation mediated polymerase chain reaction (PCR) of blunt DNA ends was used, as described previously. ${ }^{20}$

For densitometric analysis, $20 \mu \mathrm{l}$ of PCR products for each lane were loaded on $4 \%$ polyacrylamide gels, which was followed by electrophoresis, staining with a silver staining kit (Amersham Pharmacia Biotech, Buckinghamshire, UK), photography, and scanning with a scanner linked to a computer. Only bands between 150 and 1000 base pairs were considered to be fragmented DNA and served as a marker for cell death. The integrated optical density value for each lane was calculated using a Gel-Pro Analyze software (Media Cybernetics, Des Moines, Iowa, USA). Only lanes obtained on the same gel were evaluated and compared. All PCR and electrophoretic experiments were performed in duplicate. The control group signal served as the reference for

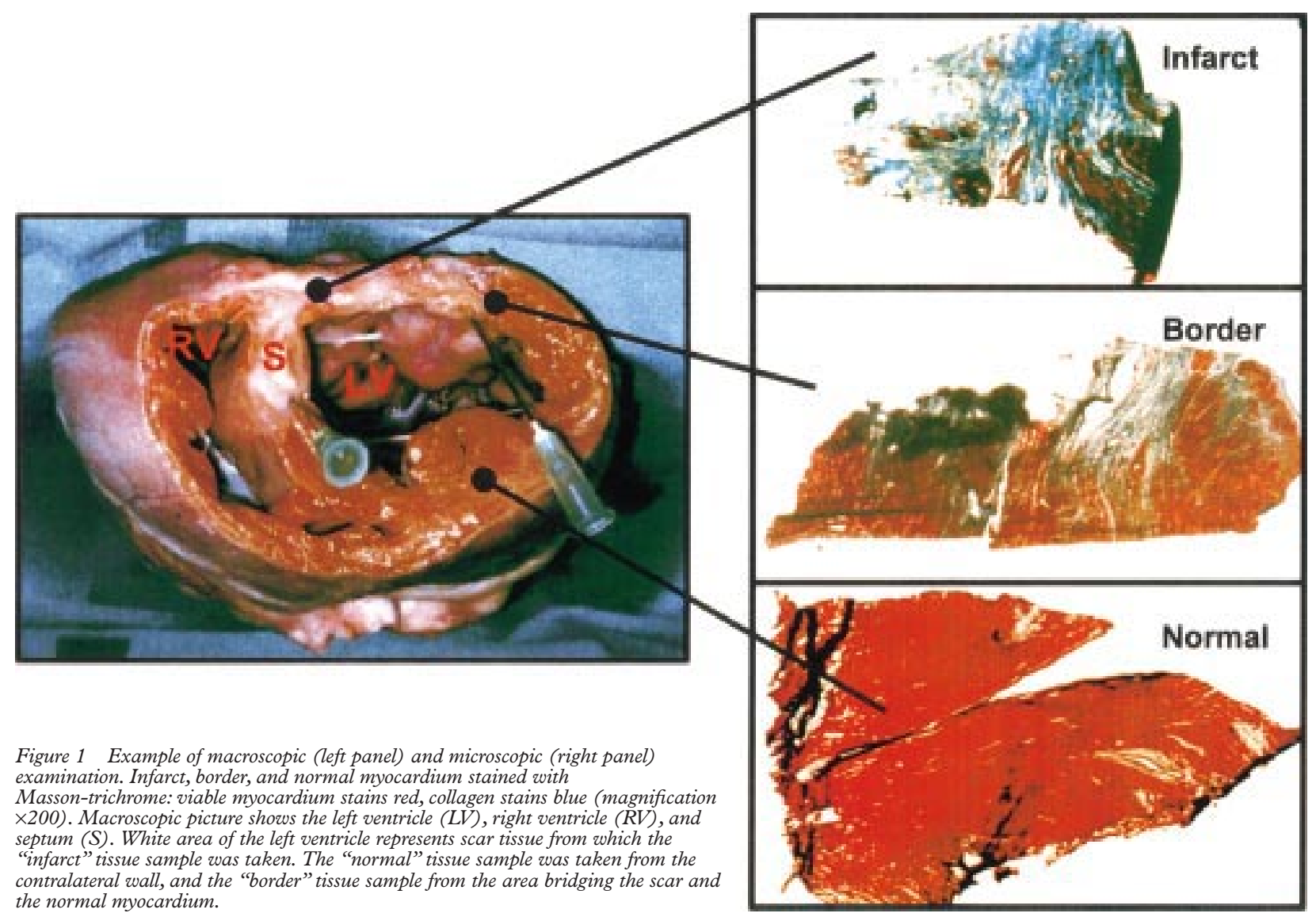


each myocardial area and was assigned a value of $100 \%$.

\section{STATISTICAL ANALYSIS}

The two way analysis of variance with repeated measures was used for comparison between IGF-I, IGF-II, and control animals. A two sample Student $t$ test assuming unequal variances was used to compare the IGF-I and IGF-II groups. The results are presented as mean (SD) (or mean (SE) for DNA laddering), and a probability value $\mathrm{p} \leqslant 0.05$ was considered significant.

\section{Results}

MYOCARDIAL FUNCTION

Segmental myocardial wall motion of IGF-I and IGF-II treated animals improved significantly during the four week period after the myocardial infarct: $0.3(0.4) v 0.6(0.7) v 1.2$ $(0.6)(\mathrm{p}=0.01)$ for IGF-I, IGF-II, and control, respectively (fig 2).

\section{MYOCARDIAL PERFUSION}

Before the myocardial infarction, myocardial perfusion was normal in all the animals. Infarction resulted in a myocardial perfusion defect that was evident in all animals. No significant differences in myocardial perfusion within the injured area were observed among the three groups, either during the four week postinfarction period $(2.38(0.75) v 2.88(0.98) v 2.25$ (1.38) for IGF-I, IGF-II, and control groups, respectively $(\mathrm{p}=0.94)$ ), or after adenosine administration (1.88 (1.16) v 2.00 (2.12) v 1.90 (1.59) for IGF-I, IGF-II, and control groups, respectively $(\mathrm{p}=0.70)$ ).

\section{BLOOD PRESSURE}

No significant differences were seen in systolic/ diastolic and mean blood pressures among the three groups of animals before infarction, immediately after infarction, or four weeks after infarction (85 (11) $v 84$ (9) $v 78$ (13) $\mathrm{mm} \mathrm{Hg}$ for mean blood pressure in IGF-I, IGF-II, and control groups four weeks after infarction, respectively $(p=0.45))$. Adenosine infusion caused a similar reduction in mean blood pressure in all animals, with no differences among the three groups (64 (9) $v 64$ (9) $v 56$ (11) $\mathrm{mm} \mathrm{Hg}$ for IGF-I, IGF-II, and control groups, respectively $(\mathrm{p}=0.28)($ table 1$)$ ).

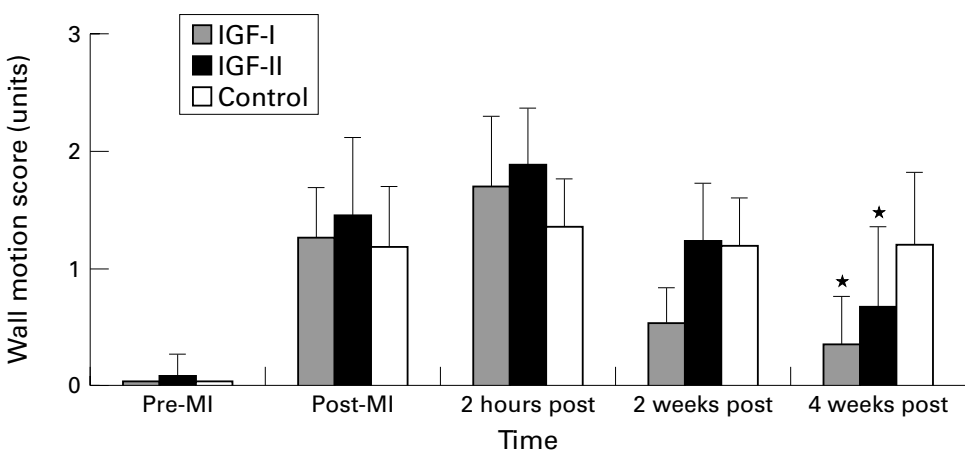

Figure 2 Comparison of myocardial wall motion abnormality in IGF-I, IGF-II, and control groups during the four week follow up period. Pre-MI, baseline; post-MI, immediately after myocardial infarction; 2 hours post, two hours after infarction; 2 weeks post, two weeks after infarction; 4 weeks post, four weeks after infarction. *Significant difference from control group, $p=0.01$.
Table 1 Changes in mean blood pressure following adenosine administration in IGF-I treated, IGF-II treated, and control animals

\begin{tabular}{|c|c|c|c|}
\hline \multirow[b]{2}{*}{ Group } & \multicolumn{2}{|c|}{ Mean blood pressure $(\mathrm{mm} \mathrm{Hg}$ ) } & \multirow{2}{*}{$\begin{array}{l}\text { Percent } \\
\text { reduction }\end{array}$} \\
\hline & Before adenosine & After adenosine & \\
\hline IGF-I & $85(11)$ & $64(9)$ & $30(3)$ \\
\hline IGF-II & $84(9)$ & $64(9)$ & $32(6)$ \\
\hline Control & $78(13)$ & $56(11)$ & $30(8)$ \\
\hline$p$ Value & 0.447 & 0.277 & 0.792 \\
\hline
\end{tabular}

Data are mean (SD).

HEART RATE

The heart rate was similar in all animals at baseline (107 (12) v 117 (15) v 112 (18) beats/ min, for IGF-I, IGF-II, and control groups, respectively $(p=0.54))$. Myocardial infarction caused an increase in heart rate in all animals, with no difference among the three groups (115 (14) v 120 (21) v 116 (10) beats/min for IGF-I, IGF-II, and control groups, respectively $(p=0.84))$. No significant differences were observed in heart rate among the three groups during the postinfarction follow up or following adenosine administration.

SERUM TROPONIN

Serum cardiac troponin I concentration in the three groups was statistically similar before and immediately after infarction. However, a significantly higher serum cardiac troponin I concentration was detected three hours after the infarction in the control group, and this increase was abolished in IGF-I and IGF-II treated animals $(1.9$ (1.2) $v 1.9$ (1.2) $v 8.0$ (3.9) $\mathrm{ng} / \mathrm{ml}$ for IGF-I, IGF-II, and control groups, respectively $(\mathrm{p}=0.001)$ (fig 3$)$ ).

ACTIN AND DESMIN

Figure 4 shows immunostaining for actin (upper panel) and desmin (lower panel) within normal, border, and infarct areas (magnification $\times 200$ ). In the normal myocardium there were no differences in the actin content among the three groups. However, in the border and infarct areas the actin content was higher in IGF-I and IGF-II treated animals than in the control group (36.7 (6.4)\% v 30.5 (3.8)\% v $25.4(4.8) \%(\mathrm{p}=0.01)$, and $4.5(0.2) \%$ v 4.4 $(0.9) \%$ v $2.1(0.9) \%(p=0.0001)$ for IGF-I, IGF-II, and control animals in the border and

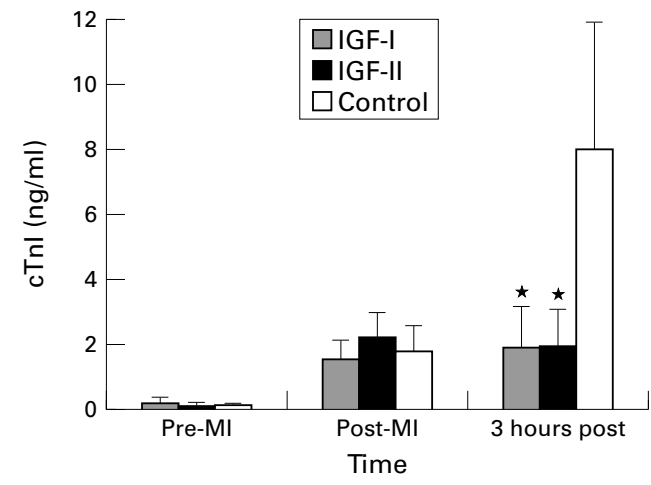

Figure 3 Comparison of serum cardiac troponin I (cTnI) concentrations in IGF-I, IGF-II, and control groups at baseline (pre-MI), immediately after myocardial infarction (post-MI), and three hours after infarction (3 hours post-MI). *Significant difference from control, $p=0.001$. 

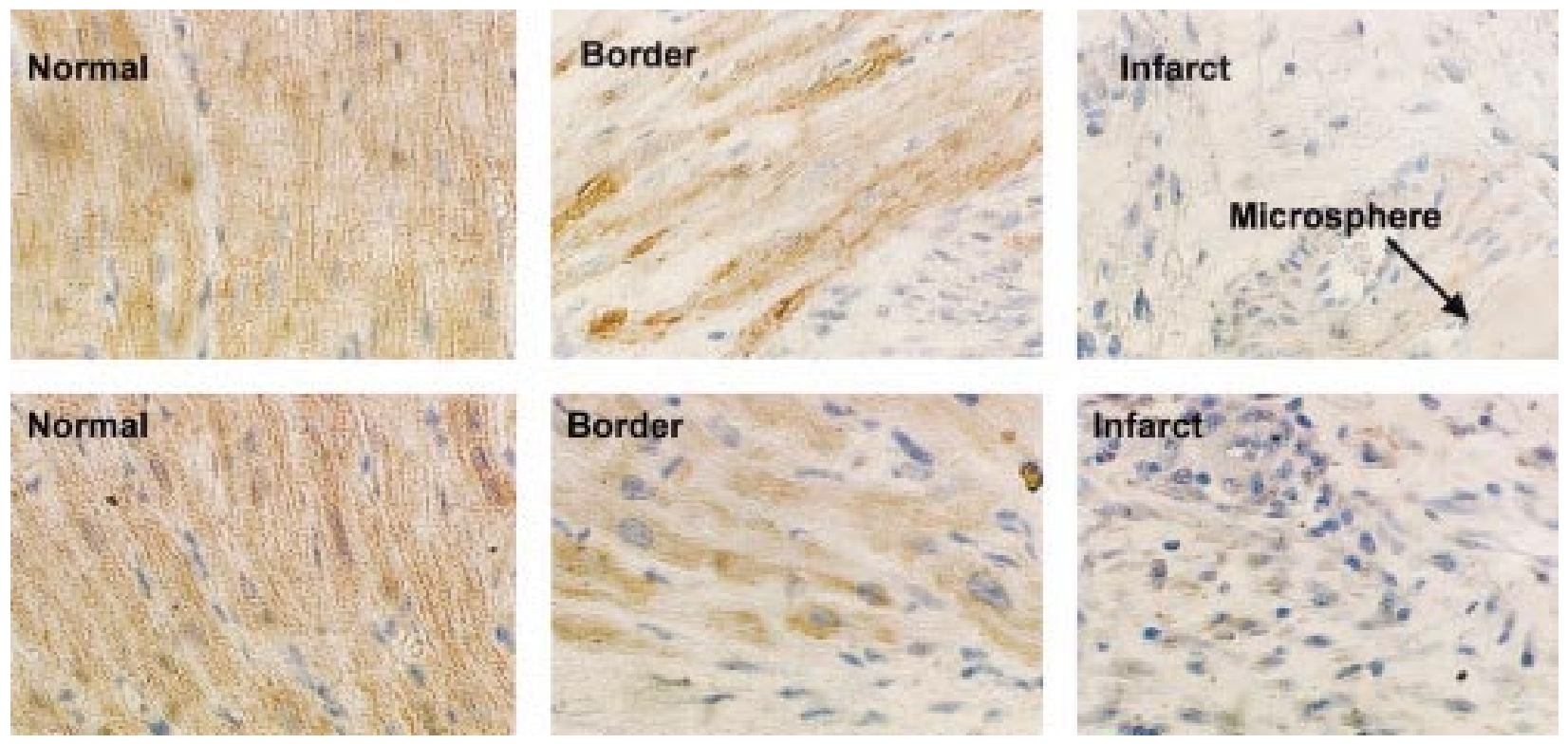

Figure 4 Immunostaining with monoclonal mouse IgG2a a-actin (upper panel) and monoclonal mouse IgG $G_{1} \kappa$ a-desmin (lower panel) of normal, border, and infarct areas. Lower staining intensity is observed within infarcted and border myocardial areas than in the normal area. A typical affigel blue bead microsphere is also shown.
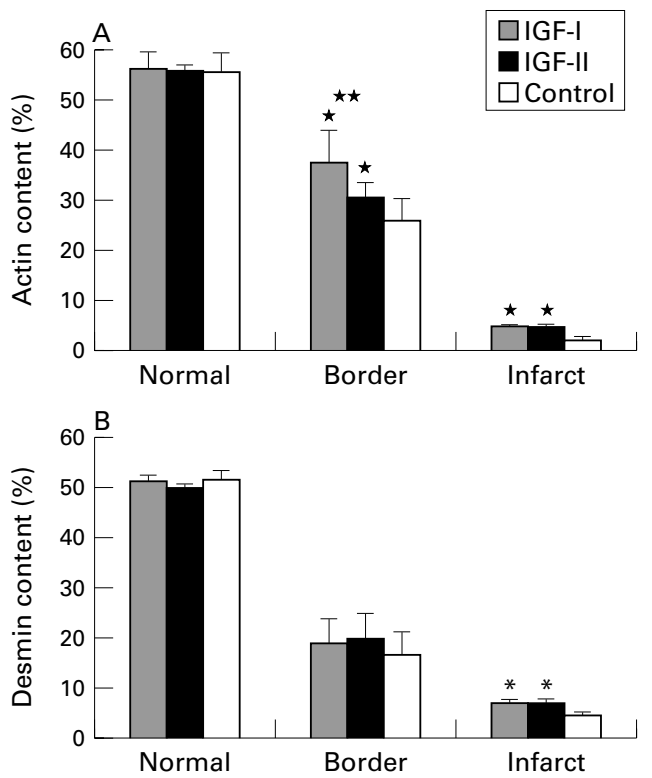

Figure 5 (A) Comparison of the actin content in the normal, border, and infarct myocardial areas of IGF-I, $I G F-I I$, and control groups. *Significant difference from control group in the border area $(p=0.01)$ and the infarct area $(p=0.0001) .{ }^{*}$ Significant difference between IGF-I and IGF-II groups in the border area $(p=0.03)$

(B) Comparison of desmin content in the normal, border, and infarct areas of IGF-I, IGF-II, and control groups. * Significant difference from control group in the infarct area ( $p=0.0002)$.

infarct areas, respectively) (fig 5A). Moreover, the IGF-I treated group had more actin in the border area than the IGF-II treated animals (36.7 (6.4)\% v 30.5 (3.8)\%, respectively $(\mathrm{p}=0.03))$.

In the normal and border areas there was no difference in desmin content among the three groups. However, the infarct area of both IGF-I and IGF-II groups had a larger desmin content than control animals $(7.0(0.9) \%$ v $7.1(1.0) \% v$ $4.4(0.8) \%$, for IGF-I, IGF-II, and control groups, respectively $(\mathrm{p}=0.0002)$ (fig $5 \mathrm{~B})$ ).
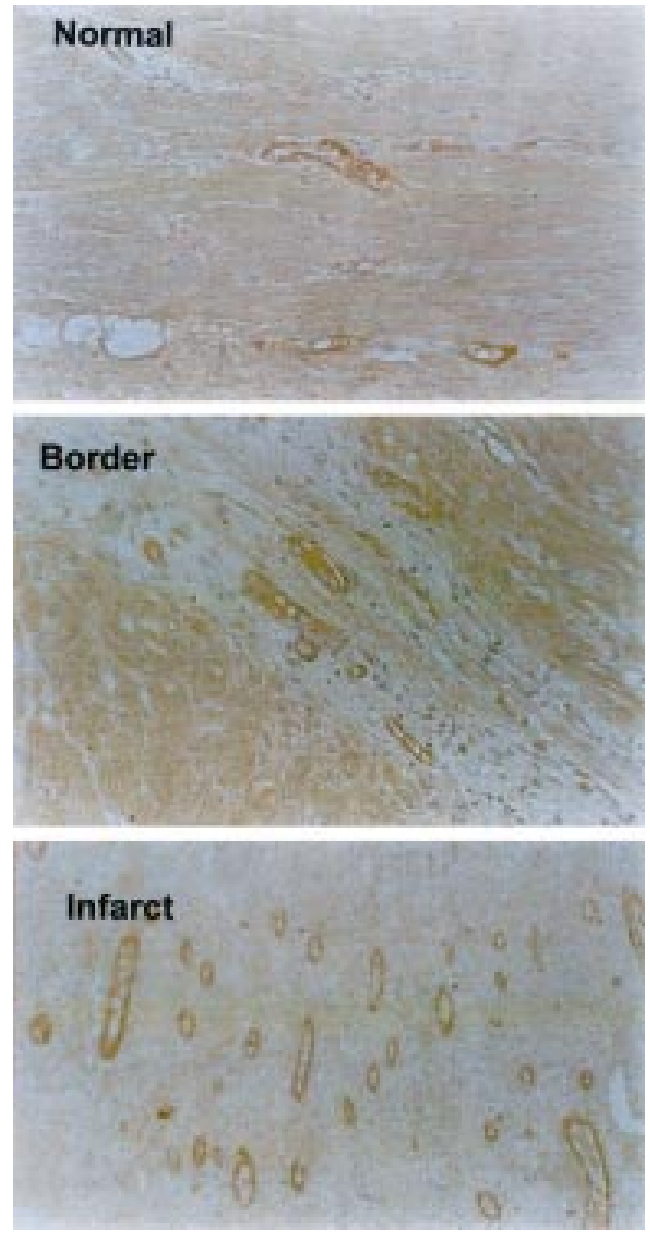

Figure 6 Immunostaining with factor VIII (Von Willebrand factor, VWF) antibody of normal, border, and infarct areas. Larger numbers of positively stained endothelial cells are seen within the infarcted myocardial area than in the border and normal areas. 


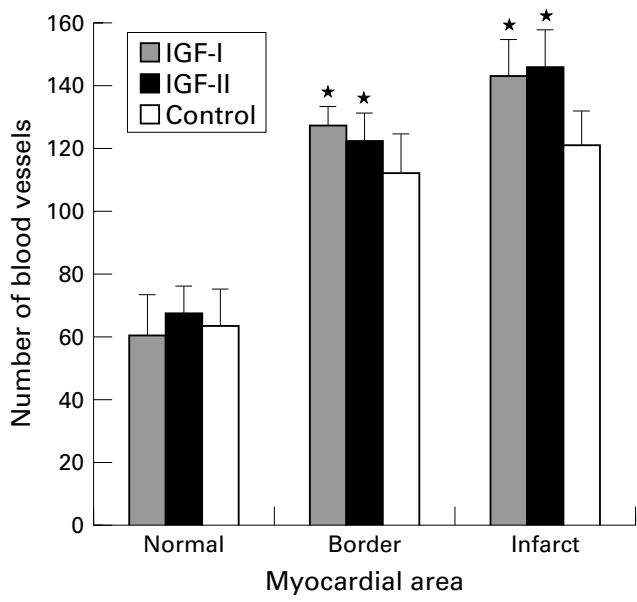

Figure 7 Comparison of blood vessel density in the normal, border, and infarct myocardial areas of IGF-I treated, IGF-II treated, and control groups. ${ }^{\star}$ Significant difference from control group in the border $(p=0.04)$ and infarct areas $(p=0.003)$.

BLOOD VESSEL DENSITY

Figure 6 shows immunostaining for factor VIII within normal, border, and infarct areas. In the normal myocardial area there was no difference in the number of blood vessels among the three groups. However, significantly more blood vessels were detected in IGF-I and IGF-II treated animals than in the control animals (127 (6) $v$ 122 (9) v 112 (12), and 143 (13) v 146 (9) v 121 (12), for IGF-I, IGF-II, and control groups in the border area $(p=0.04)$ and infarct area $(\mathrm{p}=0.003)$, respectively (fig 7$)$ ).

DNA LADDERING

Figure 8 shows typical DNA strand breaks from an animal with myocardial infarction treated with pig albumin (lanes a, b, c) and treated with IGF-I (lanes d, e, f) within normal, border, and infarct areas. A significantly larger

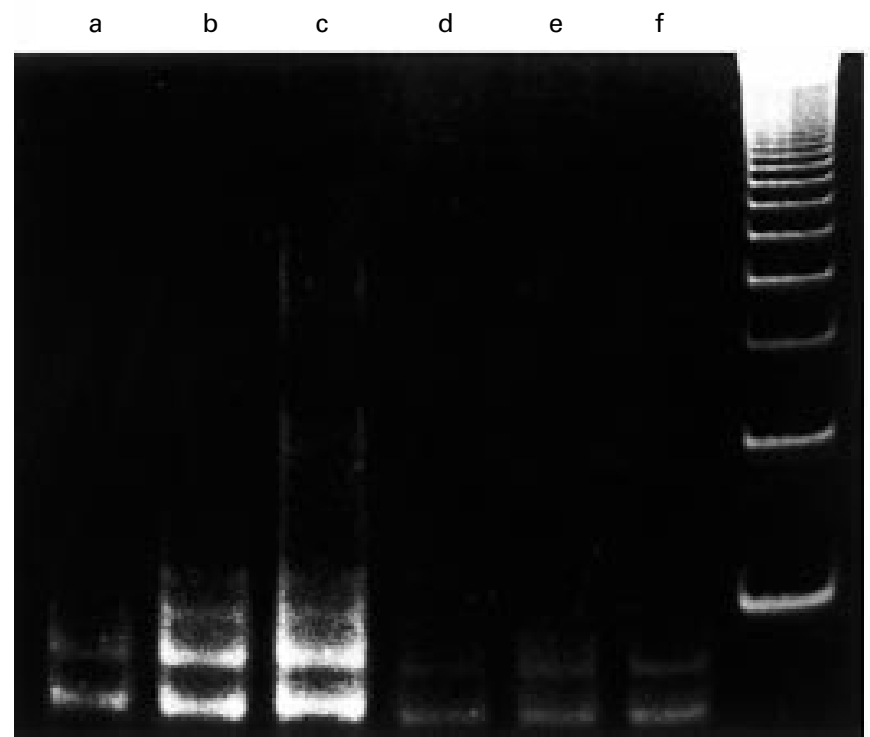

$1000 \mathrm{bp}$ $750 \mathrm{bp}$ $500 \mathrm{bp}$

Figure 8 Gel electrophoresis of DNA strand breaks (a-f) using ligation mediated polymerase chain reaction. Lanes $a, b$, and $c$ represent normal, border, and infarct areas, respectively, from a representative control animal. Lanes $d, e$, and f represent normal, border, and infarct areas, respectively, from a representative IGF-I treated animal. The right lane represents a 123 base pair ladder of double stranded DNA (D-5042, Sigma). number of DNA strand breaks is present in the control animal. No differences were observed between IGF-I and IGF-II in any myocardial area, neither was there any difference among the three groups in the normal and border areas. However, both IGF-I treated (23.3 $(8.5) \%)$ and IGF-II treated animals (33.3 $(8.3) \%$ ) showed reduced DNA laddering in the infarcted area compared with the controls $(100 \%)(\mathrm{p}<0.05)$.

\section{Discussion}

Our study shows that the exogenous administration of IGF-I and IGF-II improves regional myocardial function of injured regions in an experimental swine model of acute myocardial infarction. Although a beneficial effect of IGF variants on myocardial function has been reported previously, this is the first study comparing their effects in the same animal model of acute myocardial infarction and exploring some of the underlying mechanisms of these effects.

IGF-I AND IGF-II EFFECTS ON MYOCARDIAL FUNCTION

Accumulating evidence has indicated that IGF variants play a specific role in the intricate cascade of events of cardiovascular function, in addition to their well established growth promoting and metabolic effects. ${ }^{21}$ The effects of exogenous administration of IGF-I and IGF-II have recently been investigated. ${ }^{21}$ In a study performed by Bisi and colleagues, subcutaneous administration of a low dose of recombinant human IGF-I significantly increased basal left ventricular ejection fraction in healthy human adults. ${ }^{22}$ Intravenous administration of recombinant human IGF-I improved cardiac performance in patients with chronic heart failure by afterload reduction and possibly by positive inotropism. ${ }^{23}$ In these studies, IGF-I did not cause any haemodynamic changes..$^{22}$ Similarly, in the present study, IGF-I administration caused a significant improvement in resting myocardial function without haemodynamic changes. Thus several investigations including our own study have shown improved myocardial function in different settings of normal and pathological conditions following IGF-I administration.

In contrast to IGF-I, there are very limited data on IGF-II administration and its effects on the infarcted myocardium. Vogt and colleagues have shown that myocardial infarction was significantly decreased by direct intramyocardial infusion of IGF-II in a swine model of acute occlusion and reperfusion. ${ }^{24}$ In a previous study from our laboratory, Battler and colleagues showed improved left ventricular function following IGF-II administration, using the same animal model as in the present work. ${ }^{8} \mathrm{We}$ found that IGF-II caused an increase in regional myocardial function; however, this was smaller than that achieved with IGF-I. Thus at the doses given in the present study $(150 \mu \mathrm{g} / \mathrm{pig}$ of IGF-I and IGF-II), both IGF variants 
exerted cardioprotection following acute myocardial infarction. However, additional pharmacokinetic and pharmacodynamic studies are warranted.

PRESERVATION OF MYOCARDIAL STRUCTURE The concentration of serum cardiac troponin I detected in our present study was significantly lower in IGF-I and IGF-II treated animals compared with non-treated animals three hours after the infarction. Recently, the serum concentration of heart specific contractile troponin I has been found to be a highly sensitive marker for the detection of myocardial cell injury within the first few hours of acute coronary syndromes. ${ }^{25} 26$ Thus a reduced serum cardiac troponin I concentration suggests that the IGFs attenuate infarct induced myocardial cell injury during the early postinfarction period.

We have also detected more actin and desmin in the infarct area and more actin in the border area of IGF treated animals four weeks after infarction. The combination of increased contractile and cytoskeletal proteins in these areas, and reduced serum cardiac troponin I concentration, may reflect myocardial preservation by the IGFs. Furthermore, both IGF variants were found to stimulate protein synthesis in cardiomyocytes in vitro, an additional mechanism that may be responsible for these findings. ${ }^{27-29}$ Overexpression of IGF-I in myocytes was shown to attenuate the magnitude of accumulated damage and the extent of ongoing myocyte death in a model of coronary artery narrowing in non-transgenic and transgenic mice. ${ }^{30}$ Moreover, reduced apoptosis of cardiomyocytes associated with improved myocardial function was caused by systemically administered IGF-I in the canine model of congestive heart failure. ${ }^{31}$ Finally, IGFs were shown to protect cardiac myocytes from cell death caused by myocardial infarction. ${ }^{32-34}$ In our study, DNA laddering within the infarcted myocardial area-which may occur as a result of cell death-was significantly reduced by IGF-I and IGF-II administration. ${ }^{35}$ Cellular preservation coupled with contractile protein synthesis could explain the improved left ventricular function in IGF treated animals. Additional studies are warranted to validate these hypotheses.

ANGIOGENESIS

Direct and indirect actions of IGFs may be involved in their effect on angiogenesis. ${ }^{9-12} 36$ Kluge and colleagues found a significantly increased IGF-I mRNA expression during the period from 72-168 hours following microembolisation infarction in pigs. $^{9}$ In the present study, exogenous IGF-I and IGF-II were slowly released from the beads which induced the microembolisation infarction. We assume that the release of IGFs occurred within 2-4 days after microembolisation (unpublished data). Four weeks after infarction, both IGF-I and IGF-II were found to increase the number of blood vessels in the infarct and adjacent (border) myocardial areas. The increased blood vessel density may allow the delivery of growth factors directly to the infarcted and adjacent myocardium. Thus the initiation of angiogenesis by exogenous administration of IGFs could have contributed to the improvement in myocardial function. However, the time course of the new vessel development could not be detected in the present study and we did not demonstrate an IGF induced blood flow. On the other hand, the "no reflow" phenomenon indicates that the presence of vessels does not always indicate the presence of flow. ${ }^{37}$ Thus the present work cannot show whether increased blood vessel density reduced the infarct size in the IGF-I and IGF-II treated animals.

PROPOSED MECHANISM OF THE IGF EFFECT In ventricular biopsies from patients with isolated aortic stenosis and patients with aortic regurgitation, IGF-I formation was positively related to the velocity of circumferential fibre shortening. ${ }^{38}$ In animals, IGF-I exerted a positive inotropic effect by increasing the availability of ionised calcium, and increased the shortening magnitude of myocytes isolated from the left ventricle of healthy adult mongrel dogs and dogs with heart failure. ${ }^{39}$ Thus the improvement in myocardial function caused by IGF administration in the present study may be at least partially explained by increasing the availability of $\left[\mathrm{Ca}^{2+}\right]$. In addition, in our present study the improvement in myocardial function was associated with preservation of myocardial structure in postinfarction IGF-I and IGF-II treated animals.

The mechanisms of preservation of myocardial structure after infarction may fall into three broad categories: the first is increasing myocardial oxygen supply following infarction; the second is decreasing myocardial oxygen demand following infarction; and the third is preventing the initiation of events induced by myocardial infarction that lead to irreversible cell damage. As no significant differences in myocardial perfusion, blood pressure, or heart rate were observed among the three groups during the study, any increase in myocardial oxygen supply or decrease in myocardial oxygen demand was less likely to occur in the IGF-I and IGF-II treated animals. Thus it is conceivable that IGF administration preserved myocardial structure and so improved myocardial function in the treated animals by the third mechanism.

\section{LIMITATIONS}

Our study examined the effects of exogenous IGFs in a patchy type of myocardial infarction. This is different from the usual human form of myocardial infarction caused by occlusion of an epicardial coronary artery. The extrapolation of the results of the current study to the "homogeneous" type of myocardial infarction should be done with caution.

Myocardial perfusion was analysed and evaluated by planar scintigraphic imaging, at a resolution of approximately $10 \mathrm{~mm}$. Thus changes in small vessel circulation may go undetected. Systems with higher resolution 
should be used to examine microperfusion following myocardial infarction in this model.

We examined only a few myocardial cytoskeletal and contractile proteins in the present study. While these showed promise as possible contributors to the preserved myocardial function in IGF treated hearts, a more complete investigation should be conducted to consolidate the findings.

DNA laddering is not an adequate method for determining the type of cell death. Thus additional tests should be performed for specific definition of the mechanism of cell death in this model (that is, necrosis, apoptosis, or oncosis ${ }^{40}$ ).

CONCLUSIONS

Intracoronary administration of IGF-I and IGF-II in the postinfarction pig model caused a significant improvement in myocardial function during the early phase of myocardial infarction. This was associated with preservation of myocardial structural and contractile proteins in the infarct and border areas. These findings may form the basis for investigating the role of IGFs in the treatment of acute myocardial infarction.

The study was performed by $\mathrm{A}-\mathrm{AK}$ as part of a $\mathrm{PhD}$ degree fulfilment at Sackler Faculty of Medicine, Tel-Aviv University. We thank Pharmacia AB, Sweden, for providing us with IGF-I and IGF-II. We thank the Joan and Jaime Constantiner Institute for Molecular Genetics of Tel-Aviv University for providing us with partial financial support.

1 Le Roith D. Insulin-like growth factors. $N$ Engl $7 \mathrm{Med}$ 1997;336:633-40.

2 Colao A, Cuocolo A, Di Somma C, et al. Does the age of onset of growth hormone deficiency affect cardiac performance? A radionuclide angiography study. Clin Endocrinol 2000;52:447-55.

3 Redaelli G, Malhotra A, Li B, et al. Effects of constitutive overexpression of insulin-like growth factor-I on the mechanical characteristics and molecular properties of ventricular myocytes. Circ Res 1998;82:594-603.

$4 \mathrm{Li} \mathrm{Q}, \mathrm{Li} \mathrm{B}$, Wang X, et al. Overexpression of insulin-like growth factor-I in mice protects from myocyte death after infarction, attenuating ventricular dilation, wall stress, and cardiac hypertrophy. F Clin Invest 1997;100:1991-9.

5 Ambler GR, Johnston BM, Maxwell L, et al. Improvement of doxorubicin induced cardiomyopathy in rats treated with insulin-like growth factor I. Cardiovasc Res 1993;27:136873.

6 Buerke $M$, Murohara T, Skurk C, et al. Cardioprotective effect of insulin-like growth factor I in ischemia followed by reperfusion. Proc Natl Acad Sci USA 1995;92:8031-5.

7 Duerr RL, Huang S, Miraliakbar HR, et al. Insulin-like growth factor-I enhances ventricular hypertrophy and function during the onset of experimental cardiac failure. $\mathcal{F}$ Clin Invest 1995;95:619-27.

8 Battler A, Hasdai D, Goldberg I, et al. Exogenous insulin-like growth factor II enhances post-infarction regional myocardial function in swine. Eur Heart $f$ regional myocar

9 Kluge A, Zimmermann R, Munkel B, et al. Insulin-like growth factor $\mathrm{I}$ is involved in inflammation linked angiogenic processes after microembolisation in porcine heart. Cardiovasc Res 1995;29:407-15.

10 Akagi Y, Liu W, Zebrowski B, et al. Regulation of vascular endothelial growth factor expression in human colon cancer by insulin-like growth factor-I. Cancer Res 1998;58: 4008-14

11 Nguyen M, Shing Y, Folkman J. Quantitation of angiogenesis and antiangiogenesis in the chick embryo chorioallanotic membrane. Microvasc Res 1994;47:31-40.

$12 \mathrm{Kim} \mathrm{KW}, \mathrm{Bae}$ SK, Lee OH, et al. Insulin-like growth factor II induced by hypoxia may contribute to angiogenesis of human hepatocellular carcinoma. Cancer Res 1998.58. 348-51.

13 Battler A, Scheinowitz M, Bor A, et al. Intracoronary injection of basic fibroblast growth factor enhances angiogenesis in infarcted swine myocardium. F Am Coll Cardiol 1993;22: in infarcted
14 Schiller NB, Shah PM, Crawford M, et al. Recommendations for quantitation of the left ventricle by twodimensional echocardiography. American Society of Echocardiography Committee on Standards, subcommittee on quantitation of two-dimensional echocardiograms. $\mathcal{f} \mathrm{Am}$ Soc Echocardiogr 1989;2:358-67.

15 Baer RW, Payne BD, Verrier ED, et al. Increased number of myocardial blood flow measurements with radionuclidelabeled microspheres. Am 7 Physiol 1984;246:H418-34.

16 Zaret BL, Wackers FJT, Soufer R. Nuclear cardiology. In: Braunwald E, ed. Heart disease. A textbook of cardiovascular medicine. Philadelphia: WB Saunders, 1992:277-85.

17 Galvani M, Ottani F, Ferrini D, et al. Prognostic influence of elevated values of cardiac troponin I in patients with unstable angina. Circulation 1997;95:2053-9.

18 Davidson B, Goldberg I, Kopolovic J. Angiogenesis in uterine cervical intraepithelial neoplasia and squamous cell carcinoma: an immunohistochemical study. Int $\mathcal{f}$ Gynecol Pathol 1997;16:335-8.

19 Schwarz ER, Schaper J, vom Dahl J, et al. Myocyte degeneration and cell death in hibernating human myocardium. I Am Coll Cardiol 1996;27:1577-85.

20 Staley K, Blaschke AJ, Chun J. Apoptotic DNA fragmentation is detected by a semiquantitative ligation-mediated PCR of blunt DNA ends. Cell Death Diff 1997;4:66-75.

21 Ren J, Samson WK, Sowers JR. Insulin growth factor I as a cardiac hormone: physiological and pathophysiological implications in heart disease. $f \mathrm{Mol}$ Cell Cardiol 1999;31: 2049-61

22 Bisi G, Podio V, Valetto MR, et al. Radionuclide angiocardiographic evaluation of the cardiovascular effects of recombinant human IGF-I in normal adults. Eur $\mathcal{f}$ Endocrinol 1999;140:322-7.

23 Donath MY, Sutsch G, Yan XW, et al. Acute cardiovascular effects of insulin-like growth factor I in patients with chronic heart failure. $\mathcal{F}$ Clin Endocrinol Metab 1998;83: 3177-83.

24 Vogt AM, Htun P, Kluge A, et al. Insulin-like growth factor-II delays myocardial infarction in experimental coronary artery occlusion. Cardiovasc Res 1997;33:469-77.

25 Hamm CW, Goldmann BU, Heeschen C, et al. Emergency room triage of patients with acute chest pain by means of rapid testing for cardiac troponin T or troponin I. N Engl f Med 1997;337:1648-53.

26 Solaro RJ. Troponin I, stunning, hypertrophy, and failure of the heart. Circ Res 1999;84:122-4.

27 Fuller SJ, Mynett JR, Sugden PH. Stimulation of cardiac protein synthesis by insulin-like growth factors. Biochem $\mathcal{F}$ 1992;282:85-90.

28 Ito $\mathrm{H}$, Hiroe $\mathrm{M}$, Hirata $\mathrm{Y}$, et al. Insulin-like growth factor-I induces hypertrophy with enhanced expression of muscle specific genes in cultured rat cardiomyocytes. Circulation 1993;87:1715-21.

29 Rubin R, Baserga R. Insulin-like growth factor-I receptor. Its role in cell proliferation, apoptosis, and tumorigenicity. Lab Invest 1995;73:311-31.

$30 \mathrm{Li} \mathrm{B}$, Setoguchi $\mathrm{M}$, Wang X, et al. Insulin-like growth factor-1 attenuates the detrimental impact of nonocclusive coronary artery constriction on the heart. Circ Res 1999;84:1007-19.

31 Lee WL, Chen JW, Ting CT, et al. Insulin-like growth factor I improves cardiovascular function and suppresses apoptosis of cardiomyocytes in dilated cardiomyopathy. Endocrinology 1999; 140:4831-40.

32 Harrington EA, Bennett MR, Fanidi A, et al. c-Mycinduced apoptosis in fibroblasts is inhibited by specific cytokines. EMBO f 1994;13:3286-95.

33 Sell C, Baserga R, Rubin R. Insulin-like growth factor I (IGF-I) and the IGF-I receptor prevent etoposide-induced apoptosis. Cancer Res 1995;55:303-6.

34 Bennett MR, Evan GI, Schwartz SM. Apoptosis of human vascular smooth muscle cells derived from natural vessels and coronary atherosclerotic plaques. F Clin Invest 1995;95: 2266-74.

35 Scheinowitz M, Sangiorgi G, Spagnoli LG, et al. In vivo suppression of myocardial apoptotic cell death by insulinlike growth factor IGF-I and II [abstract]. $\mathcal{F} \mathrm{Am}$ Coll Cardiol 1998;31 (suppl):66A.

36 Engelmann GL, Campbell SE, Rakusan K. Immediate postnatal rat heart development modified by abdominal aortic banding: analysis of gene expression. Mol Cell Biochem 1996;163:47-56.

37 Gavin JB, Maxwell L, Edgar SG. Microvascular involvement in cardiac pathology. 7 Mol Cell Cardiol 1998;30:2531-40.

38 Serneri GG, Modesti PA, Boddi M, et al. Cardiac growth factors in human hypertrophy. Relations with myocardial contractility and wall stress. Circ Res 1999;85:57-67.

39 Kinugawa S, Tsutsui H, Ide T, et al. Positive inotropic effect of insulin-like growth factor-1 on normal and failing cardiac myocytes. Cardiovasc Res 1999;43:157-64.

40 Majno G, Joris I. Apoptosis, oncosis, and necrosis. An overview of cell death. Am f Pathol 1995;146:3-15. 